Article

\title{
Research on Self-Organizing Evolution Level of China's Photovoltaic Industry Chain System
}

\author{
Yiping Liu ${ }^{1}$, Jian Chen ${ }^{1,2, *(1)}$ and Lingjun Wang ${ }^{1,3}$ \\ 1 College of Economics and Management, Nanjing University of Aeronautics and Astronautics, \\ Nanjing 211106, Jiangsu, China; yuehuiling@nuaa.edu.cn (Y.L.); j00000080261@njit.edu.cn (L.W.) \\ 2 College of Economics and Management, Nanjing Forestry University, Nanjing 210037, Jiangsu, China \\ 3 School of Economics and Management, Nanjing Institute of Technology, Nanjing 211167, Jiangsu, China \\ * Correspondence: cj1125@njfu.edu.cn; Tel.: +86-158-5055-7509
}

Received: 29 January 2020; Accepted: 25 February 2020; Published: 27 February 2020

\begin{abstract}
According to the self-organizing theory, we first constructed an index system of the self-organizing evolution level of China's photovoltaic (PV) industry chain system from two aspects: of development level and synergy level. Furthermore, according to the relevant data of China's PV industry, the self-organizing evolution level of the system from 2008 to 2017 was measured and evaluated by using the system evolution level measurement model and cloud model. Finally, the GM $(1,1)$ model was used to predict the self-organizing evolution level of the system from 2018 to 2022. The results show that the overall self-organizing evolution level of China's PV industry chain system shows a rising trend in the ten years from 2008 to 2017, gradually transitioning from a low evolution level to a relatively low evolution level, with the evolution level declining in 2012 and 2015. It is expected that the self-organizing evolution level will continue to maintain a stable and orderly growth trend in the next five years, entering a medium evolution level stage from 2021. If the current evolution speed can be maintained, it is expected to reach a self-organizing evolution state in the next 20 years or so.
\end{abstract}

Keywords: PV industry chain; self-organizing evolution; evolution level

\section{Introduction}

Vigorously developing renewable energy, effectively coping with climate change, and promoting clean and low-carbon transformation of energy have become a global consensus [1]. In this context, the Chinese government has clearly proposed the phased goals of non-fossil energy development, and the development of the photovoltaic (PV) industry is an important part of it [2]. China has abundant solar energy resources, which are widely distributed. It has resource conditions and industrial base for large-scale development [3]. Simultaneously, the development of the PV industry is of great significance for adjusting the energy structure, promoting the energy production and consumption revolution, and promoting the construction of ecological civilization.

In general, the PV industry chain refers to the chain formed by the connection of PV products, which can also be called the product chain [2], the supply chain [4], or the value chain [5]. The PV industry chain mainly includes the following links: crystalline silicon, silicon ingots, silicon wafers, PV cells, PV modules, and application systems. Among them, crystalline silicon, silicon ingots, and silicon wafers belong to the upstream of the industry chain, PV cells and PV modules belong to the midstream of the industry chain, and the application system belongs to the downstream of the industry chain [6]. With the development of China's PV industry, its industry chain is constantly improving. Due to technical reasons, in the initial stage of entering the global value chain, China's PV industry mainly produced midstream products in the industry chain [7], which was in the development state of "two 
heads outside" at that time [8]. Shortly thereafter, in order to enhance cost competitiveness, many PV companies implemented a vertical integration strategy to expand production to the upstream and downstream of the industry chain. In addition, the government's relevant policies also promoted the comprehensive development of the PV industry in all aspects of the industry chain [9-12]. In 2013, China's PV industry initially established a complete industry chain [13]. In some areas where the PV industry had developed well, such as Wuxi in Jiangsu Province, the local PV industry chain was relatively perfect [8], which basically fulfilled the goal set by the central government in the 12th five-year plan [14]. In the 13th five-year plan, the government has put forward new requirements for diversified applications in the PV industry.

It can be seen from the above that although China's PV industry has formed a complete industry chain system, its connotation and extension still need to be expanded. At the same time, the policy retreat requires China's PV industry to rely more on its own strength in the future development [15-19], and the development of PV industry chain will gradually enter the stage of self-organizing evolution. According to the self-organizing theory, the self-organizing evolution is a process driven by the internal power of the system, from simple to complex, from disorder to order, from low-level order to high-level order, and finally realizes the self-organizing state [20-22]. The level of self-organizing evolution refers to the scale and degree of development of an industry in each stage from its birth to the formation of dissipative structure [23], and then to the state of self-organizing. It can measure the status and potential of self-organizing evolution. The higher the level of evolution, the closer the system is to the state of self-organizing evolution. Research has shown that China's PV industry chain system has formed a dissipative structure and is developing towards self-organizing [23], but we do not know how its evolution level is and to what extent it will reach in the future. While the evolution and development of PV industry is related to the adjustment of industrial structure and the choice of company strategy, it is of great significance to study it.

However, in the existing research on PV industry, many of them regard industry chain as an analysis tool [24-26]. Others are aimed at the PV industry chain, but they are not regarded as a system and have not been studied from the perspective of self-organizing [27-29]. Based on the four subsystems of the PV industry chain, namely, the upstream, midstream, downstream of the main chain, and auxiliary chain, and taking into account the two driving factors of synergy level and development level, this paper evaluated and predicted its self-organizing evolution level.

The main contributions of this paper are as follows: (1) Construct the evaluation index system of self-organizing evolution level of PV industry chain system. (2) Build a system evolution level measurement model to measure the self-organizing evolution level of China's PV industry from 2008 to 2017. The three eigenvalues of cloud model are used to quantitatively classify the self-organizing evolution level of the system, and then evaluate the self-organizing evolution level of China's PV industry chain system. (3) Finally, based on grey theory, the renewal GM $(1,1)$ model is used to predict the trend of China's self-organizing evolution level from 2018 to 2022.

The rest of the paper is organized as follows. The following section constructs the index system for measuring the self-organizing evolution level. In Section 3, methods used in this paper are presented. Section 4 summarizes and analyzes the results. Our conclusions and recommendations are given in the final section of the paper.

\section{PV Industry Chain System and the Construction of Its Self-organizing Evolution Level Evaluation Index System}

\subsection{PV Industry Chain System}

The PV industry chain system consists of three elements: main chain, auxiliary chain, and structural relationship (see Figure 1). 


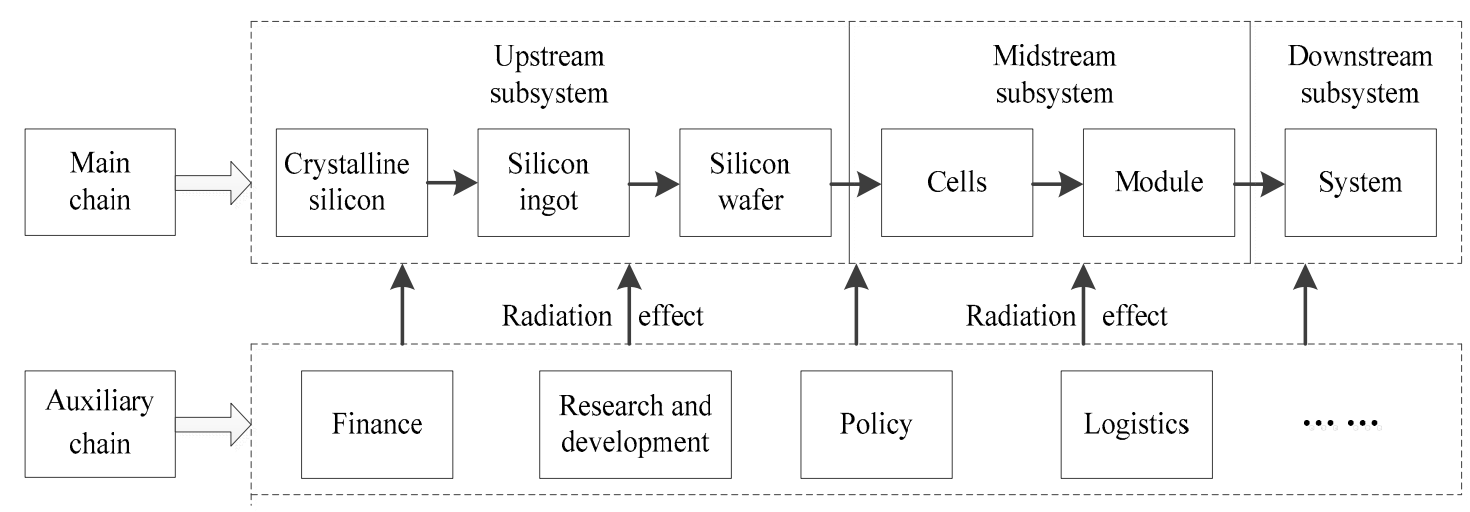

Figure 1. Photovoltaic (PV) industry chain system.

\subsubsection{Main Chain}

The main chain of the PV industry chain is a traditional product chain, which realizes the transformation from raw materials to final products. The main chain includes three subsystems: upstream subsystem, midstream subsystem, and downstream subsystem. Each subsystem of the main chain realizes cooperation and competition through the movement of information flow, material flow, and capital flow. The upstream subsystem in the main chain consists of silicon miners, silicon material producers, silicon wafer producers, etc. The midstream subsystem consists of battery chip manufacturers, battery module manufacturers, etc. Downstream subsystems include application system development enterprises, etc. These three subsystems jointly complete the exchange and transmission of material flow, capital flow, and information flow in the PV industry chain.

\subsubsection{Auxiliary Chain}

The auxiliary chain mainly provides financial, research and development, policy, auxiliary products, or labor supply and other services for the main chain. Among them, financial services are mainly provided by financial institutions such as banks and securities companies, which provide financial support for main chain node enterprises. Research and development are mainly provided by institutions of higher learning, research institutes, and other institutions, which provide strong scientific and technological innovation support for the development and growth of PV industry chain. Government departments guide the development of PV industry from a macro perspective through policies, such as financial subsidies. The main suppliers of auxiliary products or labor services are equipment manufacturers, equipment testers, PV product certification agencies, and logistics companies. Although these products and labor services do not form part of the final products of the industry chain, they contribute to the production of products.

\subsubsection{Structure Relationship}

The system structure relationship is the cooperative relationship and connection degree between the subsystems in the main chain of the industry chain and between the main chain and the auxiliary chain. The stability of the system and the distribution mode of benefits are determined by the structure relationship of the industry chain system. The main chain is a chain-like structure. The upstream, midstream, and downstream subsystems are connected by products, which develop and extend on the length of the chain to form a longitudinal product chain composed of upstream subsystem, midstream subsystem, and downstream subsystem. The development of the main chain cannot be separated from the support of auxiliary services, such as capital, research and development, policies, logistics, etc. The auxiliary chain plays a role of radiation influence on the main chain. The main chain and the auxiliary chain are interwoven with each other to become the form of chain series and broaden the width of the industry chain. 


\subsection{Construction of Self-Organizing Evolution Level Index System of PV Industry Chain System}

At present, in the research on the evaluation of industrial evolution level, some scholars have constructed an evaluation system from several dimensions (e.g., economic benefits, scientific and technological potential, environmental harmony, or development capability, innovation capability, and management capability). Each dimension selects several relevant indexes to measure and reflect the level of industrial development [30]. Some scholars also believe that the level of system evolution is affected by the degree of synergy among subsystems within the system, and it is more objective to evaluate the level of evolution based on the synergy within the system [31]. On the basis of the existing research results on the evaluation of evolution level [32-34], and the dynamic characteristics of the self-organizing evolution of PV industry chain system, this article proposed an evaluation method of the self-organizing evolution level of the PV industry chain system based on double driving factors, which evaluates the self-organizing evolution level of China's PV industry chain system from the perspectives of "development level" and "synergy level".

"Development level" means that the level of industrial evolution is affected by a series of industrial development indexes. A single index that can reflect the evolution of the system can be found from different dimensions. These indexes mainly reflect the scale and efficiency of subsystems' development. These indexes first directly affect the development of their corresponding subsystems, and then the development of each subsystem jointly affects the evolution level of the entire industry chain system. However, the level of industrial evolution is not only directly affected by a series of industrial scale efficiency development indexes, but also directly affected by the synergy level. Therefore, the level of industrial evolution is also driven by the cooperation and competition among subsystems, which is the "synergy level". Therefore, this paper holds that the self-organizing evolution level of China's PV industry chain system is driven by each single index, i.e., "development level", and is also driven by the order parameter synergy level among subsystems, i.e., "synergy level". Based on this, an index system of the self-organizing evolution level of China's PV industry chain system is constructed, as shown in Figure 2.

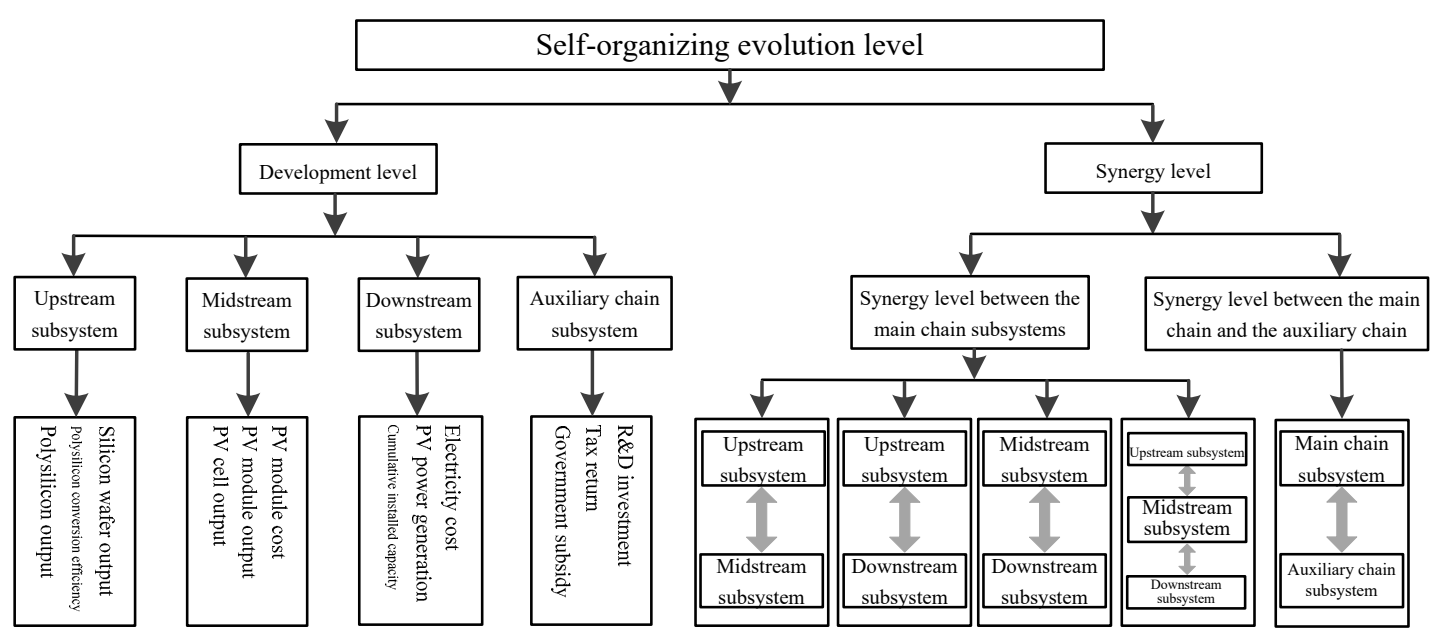

Figure 2. Evaluation index system of self-organizing evolution level of PV industry chain system.

\subsubsection{Development Level}

The development level reflects the scale or level of PV industry in different periods. The PV industry chain system consists of upstream, midstream, and downstream subsystems and auxiliary chain subsystem. Each subsystem is different and has its own characteristics. Therefore, different indexes should be selected to measure the development level of each subsystem.

The upstream subsystem of the PV industry chain is mainly engaged in the production of silicon materials, silicon ingots, and silicon wafers, providing raw materials for the midstream and downstream segments. The output and conversion efficiency of raw materials directly affect the production in the 
midstream and downstream segments; thus, affecting the development of the entire industry chain. Therefore, polysilicon output, polysilicon conversion efficiency, and silicon wafer output are selected to measure the development level of the upstream subsystem.

The midstream subsystem of the PV industry chain is composed of two parts: PV cell manufacturing and battery module manufacturing. The output of PV cells and battery modules can reflect the development status of midstream segment, and the cost of battery modules can reflect the production efficiency. Therefore, the PV cell output, the PV module output, and the PV module cost are selected to measure the development level of the midstream subsystem.

The downstream subsystem of PV industry chain is the application of PV system, forming PV power generation system, and PV application products. Cumulative installed capacity refers to the total power of all PV generating units so far. PV power generation can reflect the final product quantity of PV industry, and electricity cost reflects the technical level of PV power generation. Therefore, cumulative installed capacity, PV power generation, and electricity cost are selected to measure the development level of downstream subsystem.

In the production and operation of the main chain formed by the upstream, midstream and downstream subsystems, the radiation impact of the auxiliary chain is indispensable. The auxiliary chain includes financial enterprises, scientific research enterprises, auxiliary products or labor supply enterprises, government departments, etc. Considering the importance and availability of indexes, government subsidy, tax return, and (research and development) R\&D investment are selected to measure the development level of the auxiliary chain subsystem. Government subsidy reflects the government's policy guidance and support for the PV industry and can directly affect the development of the PV industry. Tax return reflects the government's policy incentives to the PV industry in terms of tax revenue. R\&D investment is the investment of PV industry in R\&D work, such as technological innovation, cost reduction, and efficiency improvement.

Under the influence of their respective state parameters, the four subsystems develop healthily and orderly. These state parameters jointly promote the improvement of the self-organizing evolution level of PV industry chain system.

\subsubsection{Synergy Level}

The synergy level reflects the influence of synergy and competition among subsystems on the level of system evolution. As can be seen from Figure 1, in the PV industry chain system, there are main chain subsystem and auxiliary chain subsystem. The main chain includes upstream, midstream and downstream subsystems. The subsystems of main chain interact with each other. The auxiliary chain has radiation influence on the main chain, and each subsystem is affected by different order parameters. In addition, the synergy level of PV industry chain system is affected by two parts: the synergy level between the main chain subsystems and the synergy level between the main chain and the auxiliary chain [35]. The synergy level between the main chain subsystems includes the synergy between the upstream subsystem and the midstream subsystem $\left(S_{Z 1} \& S_{Z 2}\right)$, the synergy between the upstream subsystem and the downstream subsystem $\left(S_{Z 1} \& S_{Z 3}\right)$, the synergy between the midstream subsystem and the downstream subsystem $\left(S_{Z 2} \& S_{Z 3}\right)$, and the synergy between the upstream, midstream, and downstream subsystems $\left(S_{Z 1} \& S_{Z 2} \& S_{Z 3}\right)$. The synergy level between the main chain and the auxiliary chain is the synergy between the "main chain affected by the radiation of the auxiliary chain" and the "auxiliary chain". There is competition and synergy among subsystems in China's PV industry chain system. Each subsystem develops continuously under the drive of order parameters. The "competition-cooperation-coordination" among order parameters is the driving force of system evolution. It promotes the cooperative development among subsystems and further promotes the development and evolution of the whole industry chain system. The degree of competition-cooperation-coordination among order parameters is measured by the synergy level. The higher the synergy level is, the greater the effect on the level of system evolution is. Therefore, under the action of order parameters, the degree of cooperation and competition among subsystems, 
that is, the level of cooperation, is one of the key factors driving the improvement of self-organizing evolution level.

Synergy theory holds that the order parameter comes from the macro parameters inside the system, which describes the overall situation of the system. The order parameter is the representation and measurement of the cooperative effect, controls the behavior of each subsystem in the system, and dominates the overall evolution effect of the system. Therefore, when selecting the order parameters of each subsystem, the principle is to fully represent the basic attributes of each subsystem, and the availability and authenticity of data should be considered at the same time. The output of polysilicon reflects the quantity of polysilicon produced by PV enterprises in a certain period of time. As the production of polysilicon requires a large amount of energy and expensive production equipment, it requires very high production technology and investment funds, so the output of polysilicon directly determines the starting point of PV industry. The output of PV cells is the number of PV cells generated by midstream enterprises of the industry chain within a period of time. The production of PV cells is a relatively profitable link. The output of PV cells can reflect the production and operation status of midstream enterprises of the industry chain. PV power generation is the amount of light energy directly converted into electric energy by using the PV effect of semiconductor interface, which can reflect the final results of PV industry. Government subsidy is the government's financial support for the early development of the PV industry, which can reflect the country's policy guidance for the PV industry. Therefore, polysilicon output, PV cell output, PV power generation, and government subsidy are selected as the order parameters of the upstream, midstream, downstream subsystems, and auxiliary chain subsystem, respectively. They are important influencing factors for the development of the PV industry chain system, from disordered state to ordered state, and the realization of higher-level state.

\subsection{Evaluation Criteria}

In this paper, cloud model is used to classify the level of self-organizing evolution. Cloud model is an uncertain conversion model that uses mathematical language to convert qualitative concepts into quantitative indexes. It organically combines fuzziness in fuzzy set theory with randomness in probability theory to form a mapping between qualitative and quantitative [36]. The cloud model fully considers the fuzziness and randomness of the research object. The corresponding relation of uncertainty from qualitative concept to quantitative index is established, which well overcomes the single fuzziness of fuzzy theory. In addition, it is easy to operate and can be used in various system models. Moreover, it well considers the uncertainty existing in the system, and improves the efficiency of transforming qualitative concept into quantitative index. At present, cloud model has been widely used in prediction, comprehensive evaluation, knowledge representation, and other fields $[37,38]$.

Using cloud model to classify grades, the key is to determine the membership function of each factor in the evaluation system, and the determination of this membership function mainly depends on the expectation, entropy, and super entropy of each factor. The specific calculation is as follows:

(1) Calculate expectation $E_{x}$

$$
\mathrm{E}_{\mathrm{x}}=\left(\mathrm{E}_{\mathrm{x} 1}+\mathrm{E}_{\mathrm{x} 2}+\ldots+\mathrm{E}_{\mathrm{xn}}\right) / n
$$

(2) Calculate entropy $E_{n}$

$$
\mathrm{E}_{\mathrm{n}}=\sqrt{\frac{1}{n-1} \sum_{i=1}^{n}\left(E x_{i}-E_{x}\right)^{2}}
$$

(3) Calculate super entropy $\mathrm{H}_{e}$

$$
\mathrm{H}_{\mathrm{e}}=k,
$$

where, $\mathrm{k}$ reflects the randomness of the evaluation, and its value should not be too large, otherwise the uncertainty of the evaluation will be increased, usually 0.01 , which can not only objectively reflect the randomness of the evaluation, but also simplify the evaluation process. 
Using cloud model to classify grades, the key is to determine the membership function of each factor in the evaluation system, and the determination of this membership function mainly depends on the expectation, entropy, and super entropy of each factor. In this article, the evolution level is measured by the numerical value of the interval $[0,1]$. The smaller the value is, the lower the evolution level is. Moreover, the larger the value is, the higher the evolution level is. When the evolution level reaches 1 , the system is infinitely close to and reaches the self-organizing evolution state. At the same time, experts in the PV industry are invited to assign values to "low evolution level", "relatively low evolution level", "medium evolution level", "relatively high evolution level", and "high evolution level" respectively, and use Equations (1)-(3) to calculate the expectation, entropy, and super entropy of evolution level, each level (see Table A1). Then, use the forward cloud generator to generate evolution level cloud images, and the results are shown in Figure 3.

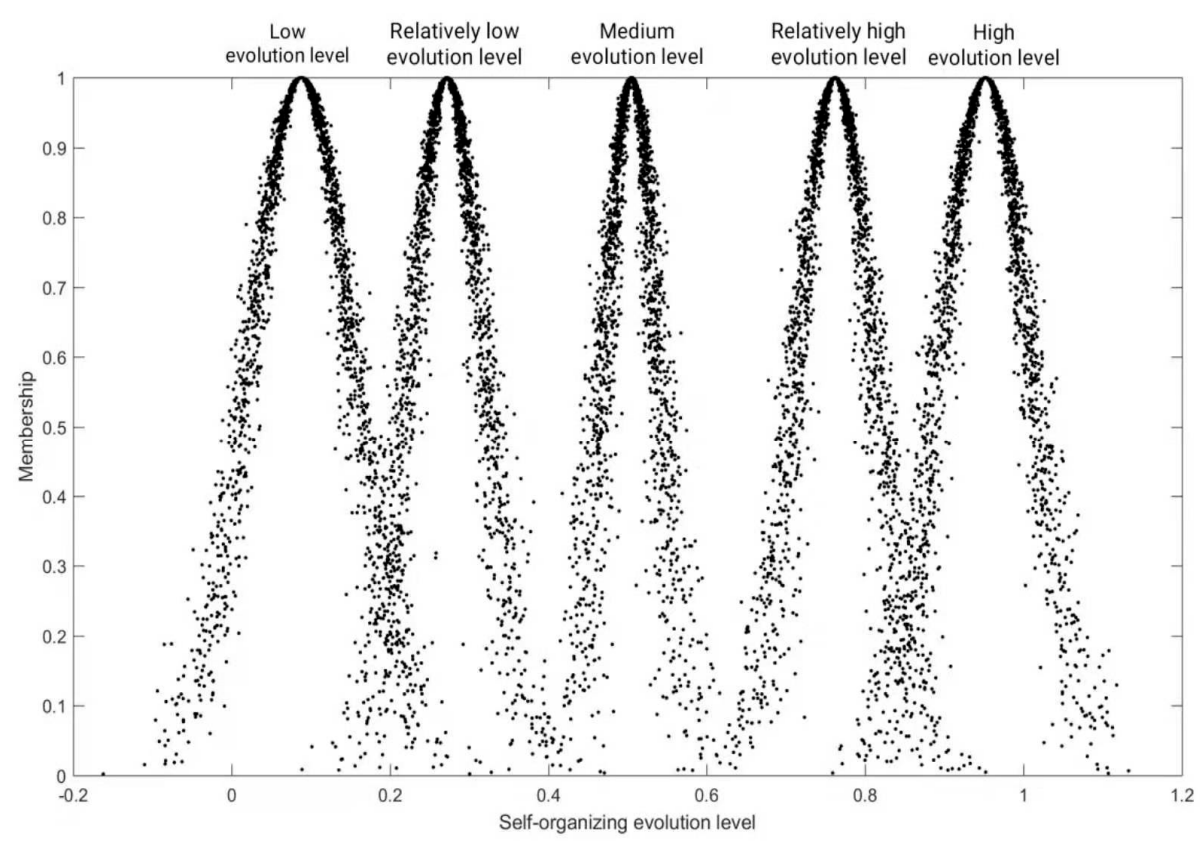

Figure 3. Cloud diagram of different grades of self-organizing evolution level.

\section{Materials and Methods}

\subsection{Analytical Framework}

This paper first calculated the development level and synergy level of PV industry chain system, then calculated and evaluated the self-organizing evolution development level of the system, and finally predicted its future self-organizing evolution development level. The specific analysis framework is shown in Figure 4.

\subsection{Data Sources}

We selected relevant data of China's PV industry from 2007 to 2017 to calculate relevant indexes. The specific data come from China and Overseas Solar PV Industry Development Report, China Statistical Yearbook, China PV Industry Development Report, PV Power Generation Industry Research Report, China Polysilicon Industry Development Report, Clean Energy Industry Report, China PV Industry Development Research Report, China Renewable Energy Development Report, China New Energy Industry Annual Report, International Renewable Energy Development Report, and other information. 


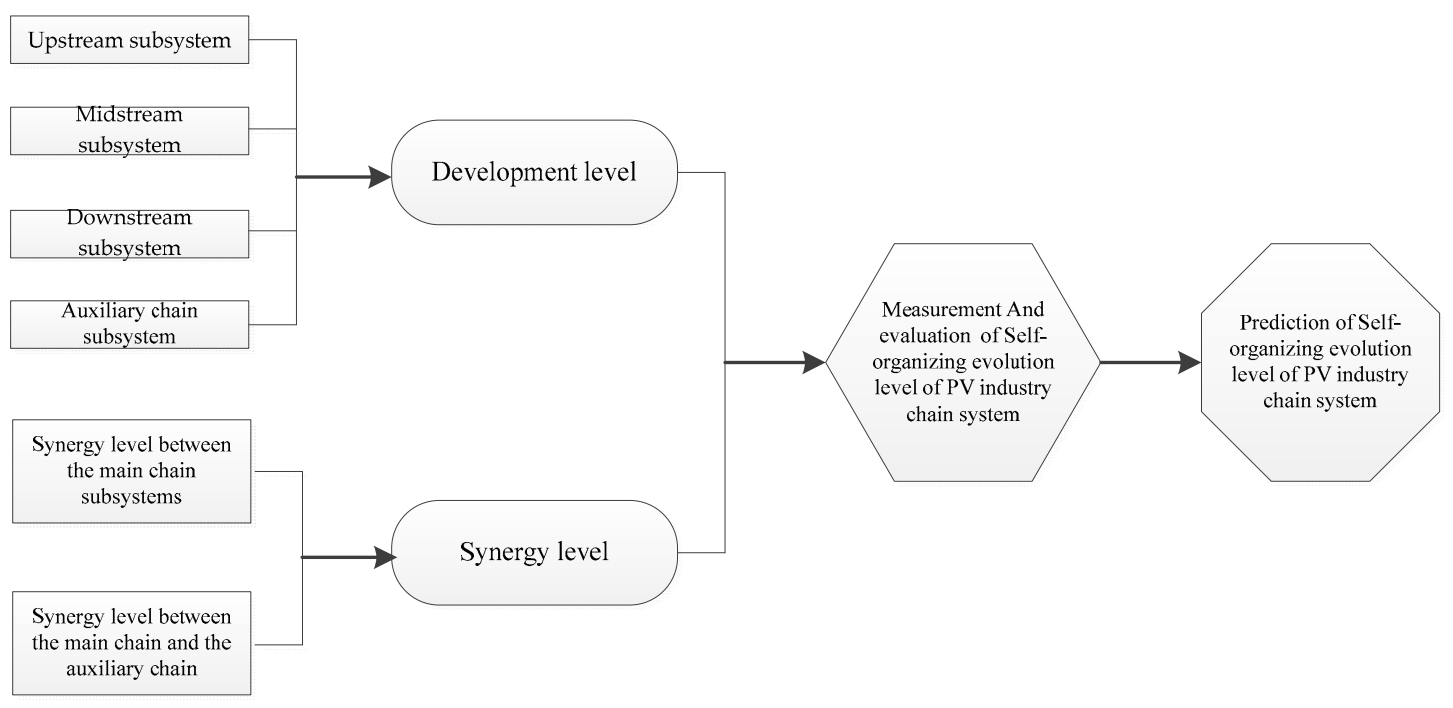

Figure 4. Analysis framework.

\subsection{Methods}

\subsubsection{Measurement Model of Development Level and Self-Organizing Evolution Level}

Assuming that the system $S$ consists of $k$ subsystems, which are expressed as $S_{1}, S_{2} \ldots S_{k}$ separately, the whole system is represented as $S=f\left(S_{1}, S_{2} \ldots S_{k}\right), f$ is composite function.

Step 1: Standardize the original data

The range standard method is used to standardize the original data of $k$ subsystem:

$$
=\left\{\begin{array}{l}
\frac{x_{i j}^{t}-\min _{i j}^{t}}{\max _{i j}^{t}-\min _{i j}^{t}}, X_{i j}(+) \\
\frac{\max _{i j}^{t}-x_{i j}^{t}}{\max _{i j}^{t}-\min _{i j}^{t}}, X_{i j}(-)
\end{array},\right.
$$

where, $x_{i j}^{t}$ is the original value of the $j$ th index in the $\mathrm{t}$ year of the subsystem $S_{i}, \mathrm{i} \in[1,2 \ldots \mathrm{k}]$ and $\max _{i j}^{t}, \min _{i j}^{t}$ are the minimum and maximum value of the jth index in the tyear of the subsystem $S_{i}$, $X_{i j}^{t}, X_{i j}^{t}$ represent the standardized data of the subsystem $S_{i}$ in the $t$ year.

Step 2: Entropy weight method is used to calculate index weight

The proportion of the jth index in all indexes in the $t$ year is as follows:

$$
p_{i j}^{t}=X_{i j}^{t} / \sum_{t=1}^{n} X_{i j^{\prime}}^{t}
$$

The information entropy of the jth index is:

$$
E_{i j}=-(\ln n)^{-1} \sum_{t=1}^{n}\left(p_{i j}^{t} \times \ln p_{i j}^{t}\right),
$$

The utility value of the jth index is:

$$
D_{i j}=1-E_{i j}
$$

The weight of the jth index is:

$$
W_{i j}=D_{i j} / \sum_{j=1}^{m} D_{i j}
$$

Step 3: Calculate the development level of computing systems 
The development level of the system $S_{i}$ is:

$$
X_{i}^{t}=\sum_{j=1}^{m} w_{i j} X_{i j^{\prime}}^{t} \sum_{j=1}^{m} w_{i j}=1,
$$

\subsubsection{Synergy Level Measurement Model}

\section{(1) Basic Model}

Step 1: Set the complex system composed of m subsystems, which are expressed as $S_{1}, S_{2}, S_{3}, \ldots, S_{m}$ separately. The whole system is recorded as $=f\left(S_{1}, S_{2}, S_{3}, \ldots, S_{m}\right), f$ is a composite function. The driving force for the system to change from disordered state to ordered state is the cooperation and competition between order parameters within the system.

The order parameters of each subsystem in the development process are:

$$
\begin{gathered}
X_{j}=X_{j 1}, X_{j 2}, \ldots, X_{j n}, n \geq 1, \\
X_{j m i n} \leq X_{j i} \leq X_{j m a x}, i \in[1, n], j \in[1, m]
\end{gathered}
$$

If $\mathrm{x}_{\mathrm{ji}}$ plays a positive role in the ordering of the system, the larger its value, the higher the ordering degree of the system, and the smaller its value, the lower the ordering degree of the system. If $x_{j i}$ plays a negative role in the ordering of the system, the larger its value, the lower the ordering degree of the system, and the smaller its value, the higher the ordering degree of the system.

Step 2: Calculate the order degree of $\mathrm{x}_{\mathrm{ji}}$ on $\mathrm{S}_{\mathrm{j}}$

$$
\mathrm{U}_{\mathrm{j}}\left(\mathrm{x}_{\mathrm{ji}}\right)=\left\{\begin{array}{l}
\frac{\left(X_{j i}-X_{j \min }\right)}{\left(X_{j \max }-X_{j \min }\right)}, X_{j i}(+) \\
\frac{\left(X_{j \max }-X_{j i}\right)}{\left(X_{j \max }-X_{j \min }\right)}, X_{j i}(-)
\end{array},\right.
$$

Step 3: The geometric average method is used to calculate the "total contribution" of the variables $x_{j}$ of the $j$ th subsystem to the order degree of the jth subsystem.

$$
\mathrm{U}_{\mathrm{j}}\left(\mathrm{x}_{\mathrm{ji}}\right)=\sqrt[n]{\prod_{i=1}^{n} \mathrm{U}_{\mathrm{j}}\left(\mathrm{x}_{\mathrm{ji}}\right)}, j \in[1, m],
$$

The larger the value of $U_{j}\left(x_{j}\right)$, the higher contribution of $x_{j}$ to the system order, the higher the system order, and vice versa.

Step 4: Set the initial time $T_{0}$, and the order degree of each subsystem is $U_{j}^{0}\left(x_{j}\right)$. When the whole composite system evolves to time $T_{1}$, the order degree of each subsystem is $U_{j}^{1}\left(x_{j}\right)$. The synergy level of the composite system is:

$$
C=\theta \sqrt[m]{\prod_{j=1}^{m}\left|\mathrm{U}_{\mathbf{j}}^{1}\left(\mathrm{x}_{\mathrm{j}}\right)-\mathrm{U}_{\mathbf{j}}^{0}\left(\mathrm{x}_{\mathrm{j}}\right)\right|}
$$

where, $\theta$ satisfy the following conditions:

$$
\theta=\frac{\min _{\mathrm{j}}\left[\mathrm{u}_{\mathrm{j}}^{1}\left(\mathrm{x}_{\mathrm{j}}\right)-\mathrm{u}_{\mathrm{j}}^{0}\left(\mathrm{x}_{\mathrm{j}}\right) \neq 0\right]}{\left|\min _{\mathrm{j}}\left[\mathrm{u}_{\mathrm{j}}^{1}\left(\mathrm{x}_{\mathrm{j}}\right)-\mathrm{u}_{\mathrm{j}}^{0}\left(\mathrm{x}_{\mathrm{j}}\right) \neq 0\right]\right|},
$$

In Equation (13), $U_{j}^{1}\left(x_{j}\right)-U_{j}^{0}\left(x_{j}\right)$ is the magnitude of the change in the system order degree of the variables in the subsystem from $T_{0}$ to $T_{1}$, which describes the degree to which the whole system 
becomes more orderly from $T_{0}$ to $T_{1}$. Moreover, it is indicated that the system has a positive degree of synergy if and only if the following formula is established:

$$
\mathrm{U}_{\mathrm{j}}^{1}\left(\mathrm{x}_{\mathrm{j}}\right)-\mathrm{U}_{\mathrm{j}}^{0}\left(\mathrm{x}_{\mathrm{j}}\right)>0, \mathrm{j} \in[0, \mathrm{~m}],
$$

Equation (14) indicates that the system is developing in a coordinated way in the time region $\left[\mathrm{T}_{0}, \mathrm{~T}_{1}\right]$, while on the contrary, it indicates that at least one subsystem in the system has not developed in an orderly direction. In particular, if $C \in[-1,0]$, it means that at least one subsystem is developing in the direction of disorder, it can be determined that the system is in the stage of non-cooperative development from $\mathrm{T}_{0}$ to $\mathrm{T}_{1}$.

\section{(2) Extended Model}

Existing models can calculate the degree of cooperation between several parallel subsystems in one-dimensional space. However, if you extend the system to two dimensions, considering the radiation effects between different hierarchical systems, we need to expand the original model. The system is extended to two dimensions, and each subsystem in the system is divided into two categories: the main chain subsystem and the auxiliary chain subsystem, which are, respectively, in two levels in the system, and interweave and influence each other to form a complex system (assuming that the main chain subsystem consists of several subsystems and the auxiliary chain subsystem is a single subsystem). Each subsystem of the main chain is independent of each other. The auxiliary chain subsystem has radiant influence on each subsystem of the main chain, the more ordered the auxiliary chain subsystem is with other subsystems, the more orderliness of the whole system can be improved, and the greater the contribution to the orderliness of the whole system. Therefore, the synergy degree of the auxiliary chain subsystem to each subsystem of the main chain can be taken as the weight of each subsystem of the main chain. The order degree of the main chain affected by the radiation of the auxiliary chain $U_{Z}$ is calculated, and then the synergy degree between the main chain order degree and the auxiliary chain order degree is calculated, according to the basic model. This not only reflects the hierarchical relationship of different subsystems in the complex system, but also reflects the radiation influence degree of the auxiliary chain subsystem on the main chain subsystem, i.e., the weight.

Set the main chain $\mathrm{S}_{Z}$ of a complex system be composed of $m$ subsystems, which are expressed as $\mathrm{S}_{\mathrm{Z1}}, \mathrm{S}_{\mathrm{Z} 2}, \mathrm{~S}_{\mathrm{Z} 3} \ldots \mathrm{S}_{\mathrm{Zm}}$ respectively, and the auxiliary chain subsystem is expressed as $\mathrm{S}_{\mathrm{F}}$. The whole system is recorded as $\mathrm{S}=\mathrm{f}\left(\mathrm{S}_{\mathrm{Z1}}, \mathrm{S}_{\mathrm{Z} 2}, \mathrm{~S}_{\mathrm{Z} 3} \ldots \mathrm{S}_{\mathrm{Zm}}, \mathrm{S}_{\mathrm{F}}\right)$ and $\mathrm{f}$ is a composite function.

The synergy degree between the auxiliary chain subsystem and the main chain subsystem is set as $C_{1}, C_{2} \ldots C_{m}$, and the weight of the main chain subsystem $\lambda_{1}, \lambda_{2} \ldots \lambda_{m}$ is calculated by the synergy degree; thus, the order degree $U_{Z}^{\prime}$ of the main chain affected by the radiation of the auxiliary chain is calculated, and then the synergy degree $C$ between the main chain and the auxiliary chain is calculated according to the order degree of the main chain and the auxiliary chain.

$$
\begin{gathered}
C_{j}=\sqrt{\left|\mathrm{U}_{\mathrm{j}}^{\mathrm{t}}\left(\mathrm{x}_{\mathrm{j}}\right)-\mathrm{U}_{\mathrm{j}}^{0}\left(\mathrm{x}_{\mathrm{j}}\right)\right| \times\left|\mathrm{U}_{\mathrm{F}}^{\mathrm{t}}(\mathrm{X})-\mathrm{U}^{0}{ }_{\mathrm{F}}(\mathrm{X})\right|}, j \in[1, m], \\
\lambda_{j}=m \times C_{j} / \sum_{j=1}^{m} C_{j}, j \in[1, m], \\
\lambda_{j}=m \times C_{j} / \sum_{j=1}^{m} C_{j}, j \in[1, m], \\
C=\theta \sqrt{\mathrm{U}_{\mathrm{Z}}^{\mathrm{t}^{\prime}} \times\left|\mathrm{U}_{\mathrm{F}}^{\mathrm{t}}(\mathrm{X})-\mathrm{U}^{0}{ }_{\mathrm{F}}(\mathrm{X})\right|},
\end{gathered}
$$

where, $\theta=\frac{\min _{j}\left[u_{j}^{1}\left(x_{j}\right)-u_{j}^{0}\left(x_{j}\right) \neq 0\right]}{\left|\min _{j}\left[u_{j}^{1}\left(x_{j}\right)-u_{j}^{0}\left(x_{j}\right) \neq 0\right]\right|}$. 
The higher the value of $C \in[-1,1]$, the higher the synergy level between systems, and vice versa. If the order degree of one subsystem is large, but the order degree of the other subsystem is small or reduced, the synergy level between systems will be affected.

\subsubsection{Renewal GM $(1,1)$ Grey Prediction Model}

According to the grey system theory, although the indications presented by the elements of the objective system are complex and changeable, its development and change have their own objective laws. The theory takes small samples with known and unknown information and uncertain systems with poor information as research objects. Through the generations, development and extraction of valuable information for some known information, the correct description of system operation behavior, and evolution law is realized, and then the quantitative prediction of its future changes can be made [39]. The dynamic prediction model based on grey system theory is called grey prediction, of which GM $(1,1)$ model, a special case of GM $(1, N)$ proposed by Deng, is the most widely used. The model has strong applicability for data processing and prediction with the characteristics of "small samples and poor information". Due to the late start of China's PV industry and the limited number of years that can obtain the original data, it is not suitable for the prediction method that requires a large amount of data. Therefore, the grey prediction model provides an effective method for predicting the self-organizing evolution level of PV industry chain system. Because the traditional GM $(1,1)$ model usually ignores the disturbance factors in the process of system evolution; thus, affecting the prediction accuracy, especially leading to poor prediction accuracy in the medium and long term [40-42], we used the renewal GM $(1,1)$ model to predict the evolution level.

The specific steps are as follows:

Step 1: generate a first-order buffer sequence.

Grey sequence can weaken the randomness of the original sequence by introducing buffer operator; thus, showing its regularity. Therefore, the first-order weakening operator D is introduced to obtain the first-order buffer sequence.

Set the original data sequence:

$$
X_{0}=(x(1), x(2), \ldots, x(n)),
$$

$\mathrm{D}$ is an average weakening buffer operator $(\mathrm{AWBO})$ and $\mathrm{D}^{2}$ is second-order weakening operator. The first-order buffer sequence is:

$$
X D=(x(1) d, x(2) d, \ldots, x(n) d),
$$

where, $x(k) d=\frac{1}{n-k+1}[x(k)+x(k+1)+\ldots+x(n)], k=1,2, \ldots, n$

The second-order buffer sequence is:

$$
X D^{2}=X D D=\left(x(1) d^{2}, x(2) d^{2}, \ldots, x(n) d^{2}\right),
$$

where, $x(k) d^{2}=\frac{1}{n-k+1}[x(k) d+x(k+1) d+\ldots+x(n) d], k=1,2, \ldots, n$

Step 2: generate an accumulation sequence.

Sequence is generated by accumulating the second-order buffer sequence

$$
X_{1}=\left\{x_{1}(i)\right\}(i=1,2, \ldots, n),
$$

where, $\mathrm{x}_{1}(\mathrm{k})=\sum_{\mathrm{i}=1}^{\mathrm{k}} \mathrm{x}(\mathrm{i}) \mathrm{d} \quad(\mathrm{i}=1,2, \ldots, \mathrm{n})$

Step 3: establish differential equations

$$
\frac{d x_{1}(k)}{d k}+a x_{1}(k)=u,
$$


where, $k=0,1, \ldots, n-1, a, u$ are the parameters to be estimated.

Rewrite it in the form of a matrix:

$$
\overline{\mathrm{Y}}=\mathrm{B} \bar{V}
$$

where, $\overline{\mathrm{Y}}=\left[\begin{array}{c}x_{0}(2) \\ x_{0}(3) \\ \vdots \\ x_{0}(n)\end{array}\right], B=\left[\begin{array}{cc}-z_{1}(1) & 1 \\ -z_{1}(2) & 1 \\ \vdots & \vdots \\ -z_{1}(n) & 1\end{array}\right], \hat{\bar{V}}=\left[\begin{array}{c}\hat{a} \\ \hat{u}\end{array}\right]$

Step 4: calculate the estimated value using the least square method

$$
\hat{\bar{V}}=\left[\begin{array}{l}
\hat{a} \\
\hat{u}
\end{array}\right]=\left(B^{T} B\right)^{-1} \bar{Y},
$$

The GM $(1,1)$ differential equation can be obtained by substituting the estimated value â, $\hat{u}$ into the equation:

$$
\hat{\mathbf{x}}_{1} k+1=\left(x_{0}(1)-\frac{\hat{\mathrm{u}}}{\hat{\mathrm{a}}}\right) e^{-\hat{a} k}+\frac{\hat{\mathrm{u}}}{\hat{\mathrm{a}}}
$$

Step 5: the above results to obtain the predicted value

$$
\hat{\mathrm{x}}_{0} k+1=\hat{\mathrm{x}}_{1} k+1-\hat{\mathrm{x}}_{1} k,
$$

Step 6: iterative prediction.

The latest data $\hat{x}_{0}(k+1)$ predicted by the $\mathrm{GM}(1,1)$ model are added to the original buffer sequence $X D$, and the earliest data are eliminated at the same time to make the sequence equal to dimensions. Then the GM $(1,1)$ model is established, so that the renewal prediction grey number is used to roll the prediction one by one; thus, replacing the prediction until the prediction target is completed, and the following sequence is obtained:

$$
\hat{\mathrm{x}}_{0}=\left(\hat{\mathrm{x}}_{0}(1), \hat{\mathrm{x}}_{0}(2), \ldots, \hat{\mathrm{x}}_{0}(n), \hat{\mathrm{x}}_{0}(n+1), \ldots, \hat{\mathrm{x}}_{0}(n+m)\right),
$$

where, $\hat{\mathrm{x}}_{0}(1), \hat{\mathrm{x}}_{0}(2), \ldots, \hat{\mathrm{x}}_{0}(n)$ are the original data and $\hat{\mathrm{x}}_{0}(n+1), \ldots, \hat{\mathrm{x}}_{0}(n+m)$ are the forecast data.

\section{Results and Analysis}

\subsection{Measurement of System Self-Organizing Evolution Level}

\subsubsection{Development Level}

According to Equations (4)-(9), MATLAB software is used to calculate the system development level of each subsystem of China's PV industry chain (see Table A2), and the results are shown in Figure 5.

From the development level chart of each subsystem in the PV industry chain, it can be seen that the development level of the four subsystems shows an upward trend on the whole, but the range is different. Among them, the development level of the upstream subsystem maintained a steady and slow growth, while the development level of the midstream subsystem decreased slightly in 2009, 2010, and 2012. The development level of downstream subsystem decreased slightly in 2011 and accelerated from 2014. The development level of the auxiliary chain subsystem showed a fluctuating upward trend, with a certain decline in 2010 and 2013. 


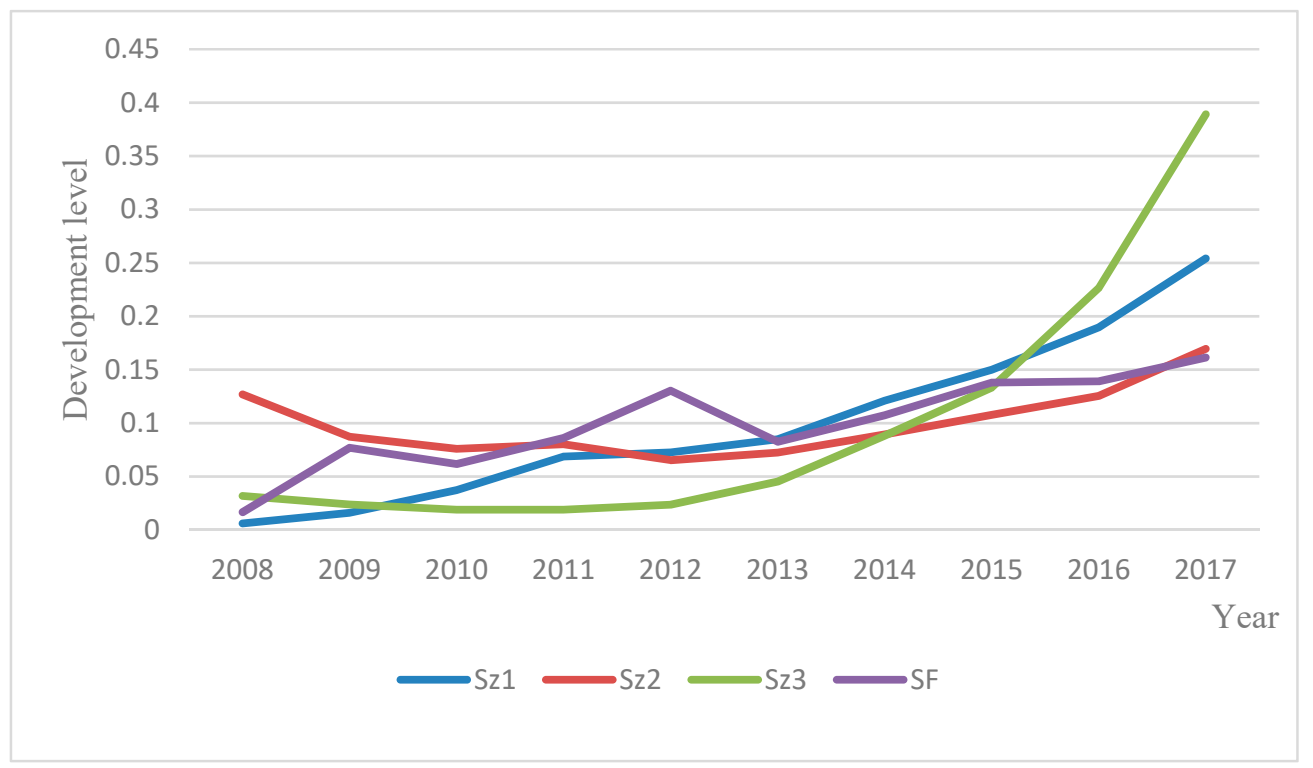

Figure 5. Development level of each subsystem of PV industry chain.

\subsubsection{Synergy Level}

According to Equations (10)-(18), MATLAB software is used to calculate the synergy level among the subsystems of China's PV industry chain (see Table A3), and the results are shown in Figures 6 and 7.

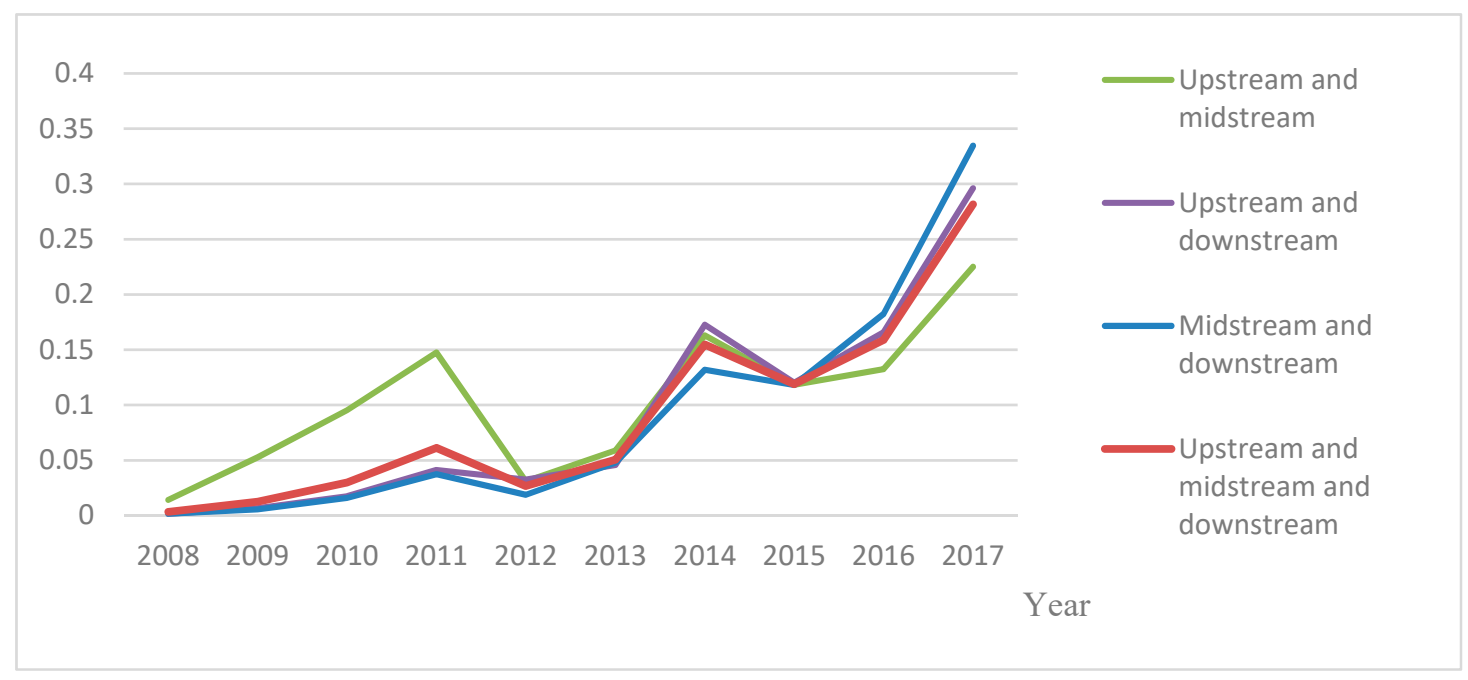

Figure 6. Synergy level between subsystems of main chain.

Judging from the synergy level among the subsystems of the main chain, from 2008 to 2017, the change trend of the synergy level among the subsystems of China's PV industry chain system was relatively consistent, showing an overall trend of improvement, but there were obvious declines in 2011-2012 and 2014-2015, obvious improvements in 2013-2014, and acceleration after 2016. It can be seen that the synergy level among subsystems is relatively low, especially the large fluctuations in 2011-2012 and 2014-2015, which makes it difficult to achieve better synergy development among subsystems in the short term and delays the synergy evolution process of the PV industry chain system to a certain extent. 


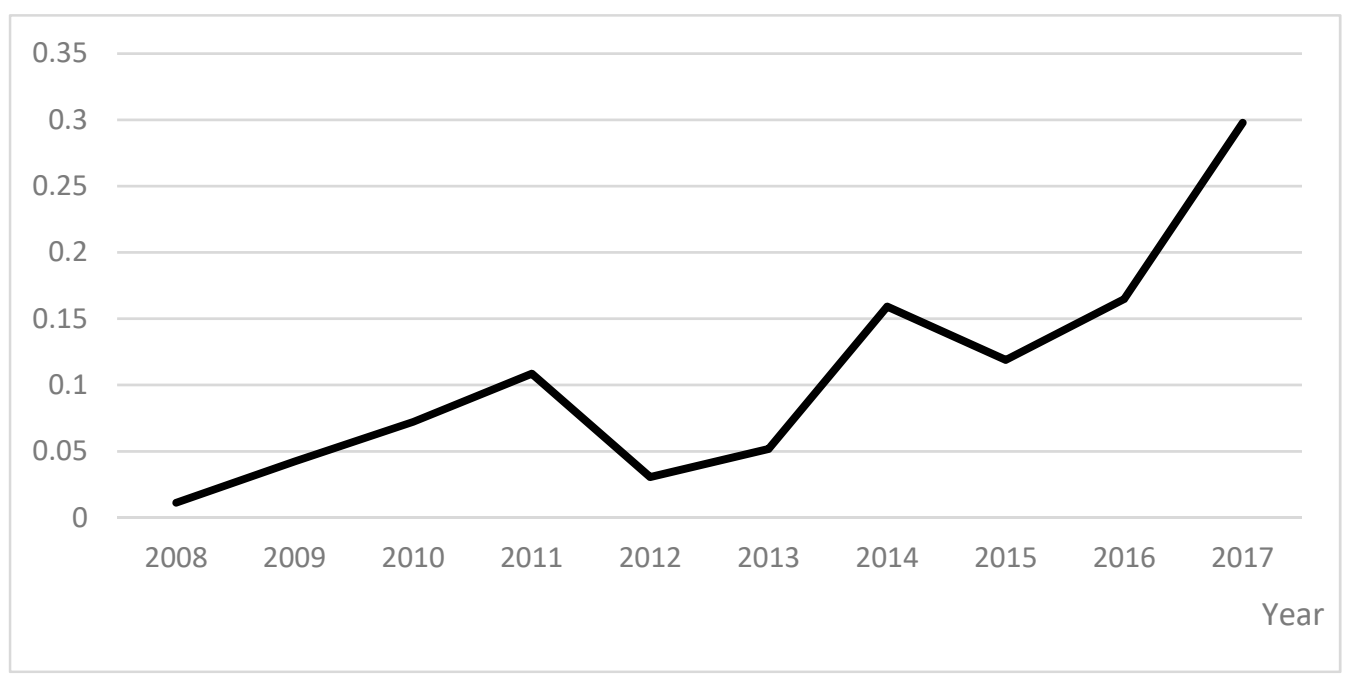

Figure 7. Synergy level between the main chain and auxiliary chain.

The synergy level between the main chain and the auxiliary chain of the PV industry chain system showed an overall upward trend from 2008 to 2017, but there was an obvious downward trend in 2011-2012 and 2014-2015, and the upward rate accelerated after 2016. Learning from the evaluation criteria of Jin (2018) and Ma (2019) on the synergy level [43,44], the synergy level between the main chain subsystems, and between the main chain and the auxiliary chain in China's PV industry chain, has been below 0.35 , which is a relatively low synergy level, but the synergy level has significantly improved in recent years. Judging from the influencing factors and existing problems, factors such as insufficient technological innovation, high cost, and insufficient government subsidies lead to imperfect chain development, and the auxiliary chain does not fully realize its radiation impact function; thus, restricting the improvement of the synergy level of the PV industry chain system.

\subsubsection{Level of Self-Organizing Evolution}

The data in Tables A1 and A2 are substituted into Equations (4)-(8) to calculate the weight of each index of the self-organizing evolution level of China's PV industry chain system (see Table 1).

Table 1. Weight of each index of self-organizing evolution level of PV industry chain system.

\begin{tabular}{ccc}
\hline First-Level Index & Secondary Index & Weight \\
\hline \multirow{3}{*}{ Development level } & $S_{Z 1}$ & 0.1049 \\
& $S_{Z 2}$ & 0.0157 \\
& $S_{Z 3}$ & 0.1907 \\
& $S_{F}$ & 0.0359 \\
Synergy level & $S_{Z 1} \& S_{Z 2}$ & 0.0695 \\
& $S_{Z 1} \& S_{Z 3}$ & 0.1778 \\
& $S_{Z 2} \& S_{Z 3}$ & 0.2036 \\
& $S_{Z 1} \& S_{Z 2} \& S_{Z 3}$ & 0.1482 \\
& $S_{Z} \& S_{F}$ & 0.0537 \\
\hline
\end{tabular}

Based on the calculation results of the above system development level and synergy level, and the weight of each index, the self-organizing evolution level of China's PV industry chain system is calculated by equation (6), and the results are shown in Table 2.

Table 2. Self-organizing evolution level of PV industry chain system from 2008 to 2017.

\begin{tabular}{ccccccccccc}
\hline Year & $\mathbf{2 0 0 8}$ & $\mathbf{2 0 0 9}$ & $\mathbf{2 0 1 0}$ & $\mathbf{2 0 1 1}$ & $\mathbf{2 0 1 2}$ & $\mathbf{2 0 1 3}$ & $\mathbf{2 0 1 4}$ & $\mathbf{2 0 1 5}$ & $\mathbf{2 0 1 6}$ & $\mathbf{2 0 1 7}$ \\
\hline Evolution level & 0.0139 & 0.0233 & 0.0335 & 0.0616 & 0.0365 & 0.0572 & 0.1465 & 0.1300 & 0.1848 & 0.3128 \\
\hline
\end{tabular}


From the calculation results in Table 2, it can be seen that the self-organizing evolution level of China's PV industry chain system has been steadily improving from 2008 to 2017, with a small decline in some years, a slow pace of improvement in the early stage, and a continuous acceleration in recent years.

\subsection{Evaluation of Self-organizing Evolution Level}

In order to see more intuitively the evolution level and trend of each year, adjust the cloud picture of the system self-organizing evolution level (Figure 3), and rotate it 90 degrees counterclockwise. Moreover, the expectation of different grades is expanded by the entropy value of up and down three times, and different levels of evolution are distinguished by different color. Then, the calculated values of self-organizing evolution level of China's PV industry chain system from 2008 to 2017 are drawn into the cloud picture, which can intuitively see the change process of the self-organizing evolution level of China's PV industry chain system in the past 10 years (see Figure 8).

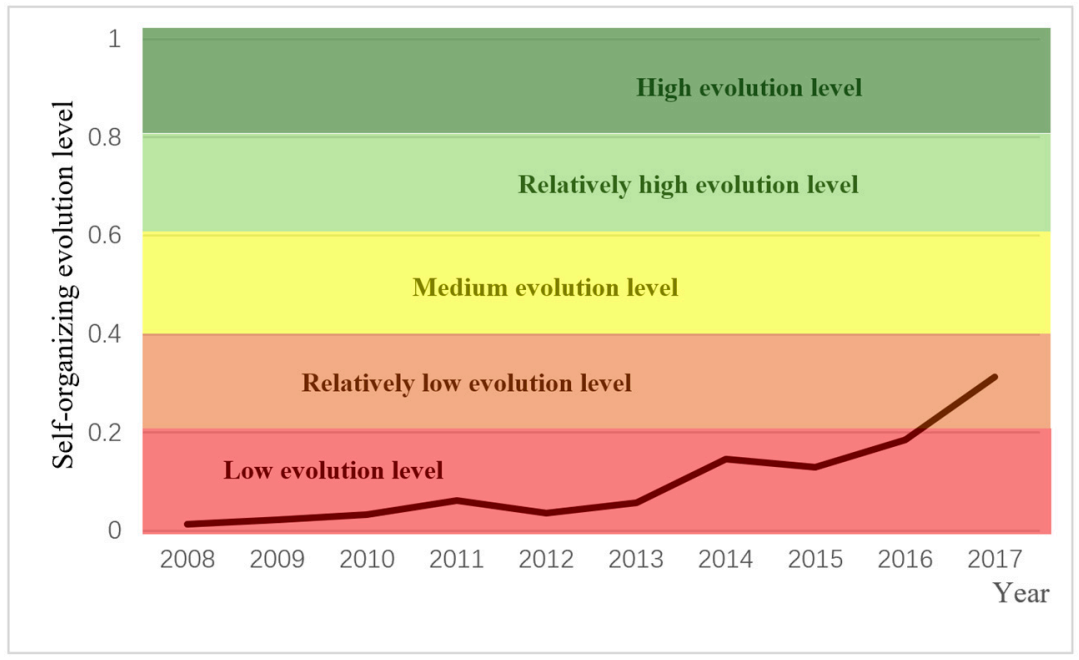

Figure 8. Self-organizing evolution level of PV industry chain system.

As can be seen from Figure 8, the evolution level of China's PV industry chain system in the ten years from 2008 to 2017 has shown an overall upward trend, with only a small decline in some years (2012 and 2015). Among them, from 2008 to 2016, it has been at a low level of evolution, and it will not enter a relatively low level of evolution until 2017. The reason for the decline in evolution level in 2012 is that China's PV industry experienced heavy losses, such as overcapacity and double opposition from Europe and United States. U.S. Commerce, which officially filed its case on 8 November, 2011, released the preliminary results of imposing a countervailing duty of $2.9 \%-4.73 \%$ on Chinese solar cells exported to the United States in March 2012. On May 17, the U.S. Department of Commerce announced that the initial anti-dumping duty rate was set at about 31\%. In the same year, the U.S. Trade Arbitration Commission announced that it would impose $18.32 \%-249.96 \%$ anti-dumping duties and $14.78 \%-15.97 \%$ anti-subsidy duties on crystalline silicon, PV cells, and modules produced in China. In addition to the "double opposition" in Europe and the United States, there are also reasons for the overcapacity of Chinese PV enterprises: in 2011, the global PV module capacity was about 60GW, of which the total capacity of existing and under construction modules in China was about 30GW, while the new installed capacity in 2011 was only 29.7 GW. The reason for the decline in evolution level in 2015 is that centralized projects connected to the grid are still unable to receive subsidies after February 2015, and the subsidy gap is also widening. On the export side, due to the European market's limited price policy towards China, the competitiveness of China's PV products in the European market has declined. Simultaneously, the sponsors of the "double opposition" are also urging the European Union's (EU's) foreign trade department to impose stricter trade sanctions on Chinese enterprises. Therefore, China's 
PV industry has risks, such as increased trade friction, economic fluctuations affecting industry trends, and instability in emerging markets. In 2015, with China's PV products exported in large quantities by virtue of their cost-effective advantages, some countries plan to increase the introduction of trade protection measures in order to reduce the impact of this fluctuation on domestic enterprises; thus, further increasing the degree of trade friction. Meanwhile, many large export enterprises in China are inclined to the Japan-US market, which makes the export structure too concentrated and risks relying too much on the single market.

\subsection{Prediction of Self-Organizing Evolution Level}

Based on the analysis of the data on the self-organizing evolution level of the PV industry chain system from 2008 to 2017 calculated in Table 2, it is found that China's PV industry had a very strong growth momentum in the evolution level from 2016 to 2017. Such high growth is mainly due to the late development of China's PV industry and its low foundation in the early stage, and it is impossible to maintain a high development speed in the future. Therefore, it is necessary to weaken the growth trend of the sequence and add the current policies, technologies, and other factors beneficial to the development of PV industry to the past years. Therefore, a second-order weakening operator $D^{2}$ is introduced to obtain a second-order buffer sequence according to Equations (19)-(21). The second-order buffer sequence is substituted into Equations (22)-(28) to obtain the predicted values from 2008 to 2017, and the relative error and average relative error between the predicted values and the original data are calculated, as shown in Table 3. It can be seen from Table 3 that the average relative error of GM $(1,1)$ model is $1.9227 \%$, and the fitting accuracy is relatively high, which can be used to predict the self-organizing evolution level of China's PV industry chain system.

Table 3. Predictive value and fitting accuracy of renewal GM $(1,1)$ model.

\begin{tabular}{cccccc}
\hline Year & Original Data & Second-Order Buffer Sequence & Predictive Value & Relative Error & Average Relative Error \\
\hline 2009 & 0.0233 & 0.182 & 0.1751 & $3.7955 \%$ & \\
2010 & 0.0335 & 0.1911 & 0.1874 & $1.9168 \%$ & \\
2011 & 0.0616 & 0.2011 & 0.2007 & $0.2228 \%$ & $1.0817 \%$ \\
2012 & 0.0365 & 0.2125 & 0.2148 & $1.6996 \%$ & $1.9227 \%$ \\
2013 & 0.0572 & 0.2261 & 0.2299 & $2.0964 \%$ & \\
2014 & 0.1465 & 0.2411 & 0.2462 & $2.5727 \%$ & \\
2015 & 0.1300 & 0.2569 & 0.2635 & $0.4586 \%$ & $1.5388 \%$ \\
2016 & 0.1848 & 0.2808 & 0.2821 & \\
2017 & 0.3128 & 0.3128 & 0.302 & $3.4604 \%$ & \\
2018 & & & 0.3233 & & $0.9240 \%$ \\
2019 & & & 0.3480 & & $0.7845 \%$ \\
2020 & & & 0.3749 & & $0.7641 \%$ \\
2021 & & & 0.4038 & & \\
2022 & & & 0.4345 & & \\
\hline
\end{tabular}

In order to further grasp the change trend of the future self-organizing evolution level of China's PV industry chain system, we carried out dynamic simulation of the evolution level based on the renewal GM $(1,1)$ prediction model of grey theory. Selecting the data of self-organizing evolution level of the PV industry chain system from 2008 to 2017, calculated above as the analysis basis, according to the above fitting model, the predicted value of the 2018 evolution level is obtained. Then, the 2009-2017 data and 2018 prediction value are formed into a new sequence, and the predicted value of the 2019 system self-organizing evolution level is obtained, according to the above prediction process, and so on, the predicted value of 2018-2022 system self-organizing evolution level is obtained. The original data for 2008-2017 and the forecast data for 2018-2022 are drawn into one chart, as shown in Figure 9.

As can be seen from Figure 9, the self-organizing evolution level of China's PV industry will continue to steadily improve in the next five years. It will still be at a relatively low evolution level from 2018 to 2020, and will enter a medium evolution level stage from 2021. From the evolution trend in the next five years, it can be predicted that, if China's PV industry can maintain the current steady and orderly development momentum, the self-organizing evolution level will gradually enter a high 
evolution level stage in the next 15 years or so, and the evolution level will reach 1 in the next 20 years or so. At this time, the PV industry chain system will reach a self-organizing evolution state.

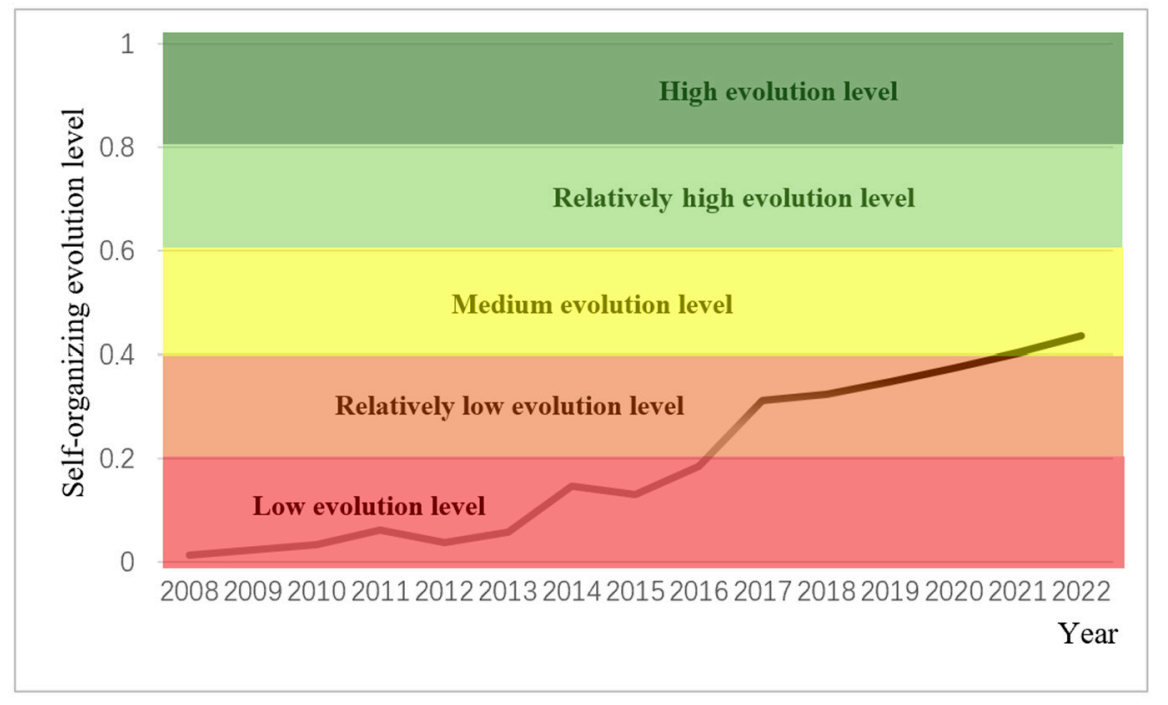

Figure 9. Forecast of self-organizing evolution level of PV industry Chain system.

According to the self-organization evolution level of the PV industry chain system predicted by renewal GM $(1,1)$ model, it can be seen that after the formation of dissipative structure in China's PV industry [23], under the joint action of the self-driving force within the subsystem, the endogenous driving force between the subsystems, the exogenous pulling force between the main chain and the auxiliary chain, and the joint driving force between the PV industry chain system and other systems, the level of self-organizing evolution and development has continuously improved and steadily evolved towards the self-organizing state. The reason for this development trend is that under the influence of PV industry policies, the PV industry will gradually change from extensive growth of pursuing scale to fine development and quality. At the same time, with the advent of the era of grid parity, cost reduction, and efficiency improvement will become the development trend of the PV industry, and the global competitiveness of China's PV industry will continue to increase in the future. According to China Photovoltaic Industry Association (CPIA) statistics, more than 20 PV enterprises in China have distributed their production capacity overseas through joint ventures, mergers and acquisitions, investments, etc. In addition, the overseas distribution of supporting products has also begun to increase, and the industrial supporting capacity of overseas bases is gradually increasing. In addition, China-EU PV trade disputes have been properly resolved, and policies conducive to the development of the industry, such as renewable energy quota system, market-oriented trading of distributed PV power generation, and management of distributed PV power generation projects, are also expected to be accelerated. All of these have laid a solid foundation for the rapid development of the PV industry in the future.

However, China's PV industry will still face some difficulties and challenges in its future development, which will affect the self-organizing evolution and development of the industry. Due to the late start of the PV industry, the current PV power generation in China does not account for a high amount of power generation in the entire power system. Although the cost of PV power generation has been reduced year by year, there is still room for further reduction. The Sino-US trade dispute and the cancellation of Sino-EU PV protection measures have brought new changes to China's foreign trade form. The development of new modes, such as household PV and building integrated PV (BIPV), brings new challenges to the PV industry. In the future, the operation and management modes, such as PV power generation systems, will be changed due to the upcoming policies, such as partition wall outlets and renewable energy quota system. 


\section{Conclusions and Recommendations}

This paper constructed an evaluation system of self-organizing evolution level of China's PV industry chain system from the perspective of dual driving factors of development level and synergy level. The system evolution level model is used to measure the self-organizing evolution level of China's PV industry chain system from 2008 to 2017. The cloud model is used to quantitatively divide the system self-organizing evolution level, and the self-organizing evolution level of China's PV industry chain system and its change trend in the past ten years are evaluated. Finally, the renewal GM $(1,1)$ grey prediction model is used to predict the self-organizing evolution level of China's PV industry chain system in the next five years. The results show that the overall self-organizing evolution level of China's PV industry chain system shows a rising trend in the ten years from 2008 to 2017, gradually transitioning from a low evolution level to a relatively low evolution level with the evolution level declining in 2012 and 2015. It is expected that the self-organizing evolution level will continue to maintain a stable and orderly growth trend in the next five years, entering a medium evolution level stage from 2021. If the current evolution speed can be maintained, it is expected to reach a self-organizing evolution state in the next 20 years or so. In order to meet the challenges in the future, promote the stable and orderly improvement of the self-organizing evolution level of the PV industry chain system, and finally reach the self-organizing evolution state, the PV industry should continuously explore from the following aspects:

(1) Establish and perfect supporting policies and supervision system for policy benefits

The development of PV industry cannot be separated from the support of government policies. Although China's government has continuously formulated a series of policies and regulations conducive to the development of PV industry in recent years, there will continue to be various problems that need to be solved jointly with government departments in the development process of emerging industries. Therefore, it is an eternal task to continuously improve laws and regulations in all aspects of the development of PV industry. Relevant government departments and PV enterprises in China should strengthen communication and cooperation with PV developed countries. Combined with the characteristics of China's photovoltaic industry development, the government should uniformly plan, formulate, improve, and implement standardized photovoltaic industry standards. Moreover, it is also needed to relax the project approval system, improve, and implement industrial policies, tax policies, financial policies, and other policies and regulations conducive to promoting the development of the PV industry, and formulate corresponding development strategies. We should improve relevant incentive policies, encourage more talents, technologies, funds, and enterprises to invest in the PV industry, and guide and support domestic PV enterprises to invest and build factories abroad. At the same time, the government should also establish a supervision system for policy benefits. According to statistics, half of the government's subsidies for new energy resources belong to the PV industry, but PV power generation can only provide $3 \%$ of the total electricity demand, and the proportion of input and output is extremely uncoordinated. To explore the reasons, there are some enterprises that lack competitive advantages to cheat government subsidies through bad means. Some enterprises have lost the motivation to continuously improve their productivity after receiving generous subsidies. These reasons have led to the fact that high government investment has not effectively promoted the development of PV industry technology. Therefore, while formulating supporting policies, the government should establish a complete supervision system for policy benefits, strictly examine and approve the qualifications of policy beneficiaries, supervise their production and operation after enjoying the policies, and assess the benefits of the policies, so that the government supporting policies can be truly invested in advanced productivity and promote industrial development.

(2) Strengthen scientific and technological innovation

The fundamental way out for the development of China's PV industry is to intensify the research, development, and innovation of key technologies, promote the transformation of PV industry from 
market-driven to innovation-driven, and continuously improve the competitive strength of PV products. PV enterprises should make continuous breakthroughs in innovative technologies to improve the absorption rate of advanced technologies. Pay attention to the advanced technological research results at home and abroad, and make adjustments and responses to development strategies, production methods, and products at all times. In addition to direct application, foreign advanced technologies that can be introduced should be absorbed and transformed into a driving force for further innovation. At the same time, we should strengthen the protection of intellectual property rights to ensure the innovation enthusiasm of PV enterprises. As soon as possible, develop and produce storage batteries with less pollution and easy recycling. Technological innovation cannot be separated from R \& D personnel. As China's research on PV industry is still at a medium level, the relevant R \& D personnel in research institutes are not sufficiently reserved, and there are few specialized courses in PV direction in institutions of higher learning. The cultivation of PV professionals is an important issue restricting the development of China's PV industry. The government should deploy the cultivation and training of leading talents in the PV industry, lead China's universities, and research institutions to jointly implement technological innovation, and combine the cultivation of talents, technological innovation, and the evolution of the PV industry in many aspects. We will increase technological exchanges and cooperation with foreign advanced scientific research institutions and enterprises, and introduce and train high-tech talents. Meanwhile, we will vigorously provide a good investment environment, attract foreign companies with relevant high technologies to enter China, and introduce innovative technologies in the form of joint ventures and cooperation.

(3) Scientific planning, integration of resources, and construction of a sound industry chain system

The PV industry should efficiently integrate and optimize resources, and eliminate backward production capacity. For example, those large-scale enterprises with advanced technology and super competitiveness can consider merging PV enterprises with low technical level and low production efficiency to realize effective integration of resources. In the construction of PV industry chain, vertical integration and horizontal integration are organically combined. Powerful PV enterprises can continue to extend the internal industry chain to the front and back ends of the chain to realize the vertical integration of the industry chain. Simultaneously, PV enterprises should also strengthen the division of labor and cooperation with other external enterprises, give full play to each enterprise's own advantages, expand its scale and strength, and form an industry chain system, integrating $\mathrm{R} \& \mathrm{D}$ design and after-sales service.

\section{(4) Action plan to promote intelligent PV industry}

The PV industry should constantly innovate in the process of development. In the process of power generation, it can be combined with other industries to create greater benefits and production capacity. "PV +" was born from this, and the combination of PV and agriculture, PV and construction, $\mathrm{PV}$ and Internet will become the development direction of innovative industries in the future. So, on the basis of "PV +" development, we should fully implement "Made in China 2025" and "Intelligent PV Industry Development Action Plan (2018-2020)", so that to promote the intelligent upgrading of the PV industry, and advocate the application of big data, narrow band internet of things (NB-IOT), and other information technologies to the PV industry. With this, we can promote the sustainable development of the PV industry.

Author Contributions: Conceptualization, Y.L. and J.C.; methodology, Y.L.; validation, Y.L.; formal analysis, L.W.; investigation, L.W.; data curation, L.W.; writing-original draft preparation, J.C.; writing-review and editing, J.C. All authors have read and agreed to the published version of the manuscript.

Funding: This research was funded by Youth Science and Technology Innovation Fund of Nanjing Forestry University (Grant Nos. CX2017016).

Conflicts of Interest: The authors declare no conflict of interests regarding the publication of this paper. 


\section{Appendix A}

Table A1. Cloud model eigenvalue of different grades of self-organizing evolution level.

\begin{tabular}{cccc}
\hline Evolution Level & Ex & En & He \\
\hline Low & 0.088 & 0.0655 & 0.01 \\
Relatively low & 0.272 & 0.0466 & 0.01 \\
Medium & 0.505 & 0.035 & 0.01 \\
Relatively high & 0.762 & 0.0485 & 0.01 \\
high & 0.9520 & 0.0575 & 0.01 \\
\hline
\end{tabular}

\section{Appendix B}

Table A2. Development level of PV industry chain system from 2008 to 2017.

\begin{tabular}{ccccccccccc}
\hline Index/Year & $\mathbf{2 0 0 8}$ & $\mathbf{2 0 0 9}$ & $\mathbf{2 0 1 0}$ & $\mathbf{2 0 1 1}$ & $\mathbf{2 0 1 2}$ & $\mathbf{2 0 1 3}$ & $\mathbf{2 0 1 4}$ & $\mathbf{2 0 1 5}$ & $\mathbf{2 0 1 6}$ & $\mathbf{2 0 1 7}$ \\
\hline$S_{Z 1}$ & 0.0061 & 0.016 & 0.0373 & 0.0686 & 0.0726 & 0.0848 & 0.121 & 0.1498 & 0.1896 & 0.2541 \\
$S_{Z 2}$ & 0.1268 & 0.0873 & 0.076 & 0.0802 & 0.0653 & 0.0724 & 0.0893 & 0.1077 & 0.1255 & 0.1695 \\
$S_{Z 3}$ & 0.0319 & 0.0239 & 0.019 & 0.0189 & 0.0237 & 0.0453 & 0.0883 & 0.1333 & 0.2266 & 0.3891 \\
$S_{F}$ & 0.0166 & 0.0768 & 0.0617 & 0.0861 & 0.1304 & 0.0826 & 0.1073 & 0.138 & 0.1392 & 0.1614 \\
\hline
\end{tabular}

Table A3. Synergy level of PV industry chain system from 2008 to 2017.

\begin{tabular}{ccccccccccc}
\hline Index/Year & $\mathbf{2 0 0 8}$ & $\mathbf{2 0 0 9}$ & $\mathbf{2 0 1 0}$ & $\mathbf{2 0 1 1}$ & $\mathbf{2 0 1 2}$ & $\mathbf{2 0 1 3}$ & $\mathbf{2 0 1 4}$ & $\mathbf{2 0 1 5}$ & $\mathbf{2 0 1 6}$ & $\mathbf{2 0 1 7}$ \\
\hline$S_{Z 1} \& S_{Z 2}$ & 0.0142 & 0.0528 & 0.0954 & 0.1476 & 0.0311 & 0.0590 & 0.1630 & 0.1183 & 0.1324 & 0.2251 \\
$S_{Z 1} \& S_{Z 3}$ & 0.0017 & 0.0068 & 0.0175 & 0.0413 & 0.0327 & 0.0459 & 0.1726 & 0.1203 & 0.1659 & 0.2961 \\
$S_{Z 2} \& S_{Z 3}$ & 0.0016 & 0.0056 & 0.0161 & 0.0376 & 0.0188 & 0.0479 & 0.1319 & 0.1182 & 0.1825 & 0.3346 \\
$S_{Z 1} \& S_{Z 2} \& S_{Z 3}$ & 0.0034 & 0.0127 & 0.0299 & 0.0612 & 0.0268 & 0.0506 & 0.1548 & 0.1189 & 0.1589 & 0.2815 \\
$S_{Z} \& S_{F}$ & 0.0429 & 0.0853 & 0.0762 & 0.1782 & 0.0265 & 0.0601 & 0.2048 & 0.0740 & 0.0984 & 0.1362 \\
\hline
\end{tabular}

\section{References}

1. Wang, Z.; Wei, W. External cost of photovoltaic oriented silicon production: A case in China. Energy Policy 2017, 107, 437-447. [CrossRef]

2. Grau, T.; Huo, M.; Neuhoff, K. Survey of photovoltaic industry and policy in Germany and China. Energy Policy 2012, 51, 20-37. [CrossRef]

3. Wu, T.; Zhou, W.; Yan, X.; Ou, X. Optimal policy design for photovoltaic power industry with positive externality in China. Resour. Conserv. Recycl. 2016, 115, 22-30. [CrossRef]

4. Chen, H.H.; Pang, C. Organizational forms for knowledge management in photovoltaic solar energy industry. Knowl. Based Syst. 2010, 23, 924-933. [CrossRef]

5. Zhang, F.; Gallagher, K.S. Innovation and technology transfer through global value chains: Evidence from China's PV industry. Energy Policy 2016, 94, 191-203. [CrossRef]

6. Wang, W.; Shi, Y. The Formation of China's Photovoltaic Industry Dilemma: Path, Mechanism and Policy Reflection. Contemp. Financ. Econ. 2014, 350, 87-97. [CrossRef]

7. Geng, Y.; Zhou, X. The Development Path of Solar Photovoltaic Industry. China Soft Sci. 2010, 4, 19-28+134. [CrossRef]

8. Tong, X.; Wang, T.; Li, M. Global-Local Linkages in Photovoltaic Industry in Wuxi, China. Sci. Geogr. Sin. 2017, 37, 1823-1830. [CrossRef]

9. Gruss, L.; ten Brink, T. The Development of the Chinese Photovoltaic Industry: An advancing role for the central state? J. Contemp. China 2016, 25, 453-466. [CrossRef]

10. Dominguez Lacasa, I.; Shubbak, M.H. Drifting towards innovation: The co-evolution of patent networks, policy, and institutions in China's solar photovoltaics industry. Energy Res. Soc. Sci. 2018, 38, 87-101. [CrossRef]

11. Zhu, X.; He, C.; Mao, X.; Li, W. The Spatial Pattern of China PV Industry under the Background of Trade Protectionism. Econ. Geogr. 2018, 38, 98-105. [CrossRef] 
12. Guo, B.; Li, J.; Zhang, X. Influences of policy coordination on policy effectiveness: An empirical study based on 227 Chinese photovoltaic industry policies. Stud. Sci. Sci. 2018, 36, 790-799. [CrossRef]

13. Ming, Z.; Shaojie, O.; Hui, S.; Yujian, G. Is the "Sun" still hot in China? The study of the present situation, problems and trends of the photovoltaic industry in China. Renew. Sustain. Energy Rev. 2015, 43, 1224-1237. [CrossRef]

14. He, X. Solar Power Development in China. Compr. Guide Sol. Energy Syst. 2010, 132, 19-35. [CrossRef]

15. Xiong, Y.; Yang, X. Government subsidies for the Chinese photovoltaic industry. Energy Policy 2016, 99, 111-119. [CrossRef]

16. Zhang, Y.; Zhao, X.; Zuo, Y.; Ren, L.; Wang, L. The Development of the Renewable Energy Power Industry under Feed-In Tariff and Renewable Portfolio Standard: A Case Study of China's Photovoltaic Power Industry. Sustainability 2017, 9, 532. [CrossRef]

17. Long, R.; Cui, W.; Li, W. The Evolution and Effect Evaluation of Photovoltaic Industry Policy in China. Sustainability 2017, 9, 2147. [CrossRef]

18. Fan, R.; Dong, L. The dynamic analysis and simulation of government subsidy strategies in low-carbon diffusion considering the behavior of heterogeneous agents. Energy Policy 2018, 117, 252-262. [CrossRef]

19. United Research Group of China Center for Energy and Development at the National School of Development, Peking University; Department of Energy Economics at the School of Economics, Renmin University of China; Wang, M. Subsidy Crisis and Large-Scale Curtailment of Wind and Solar Power in China. Int. Econ. Rev. 2018, 4, 67-85.

20. Haken, H. Information and Self-Organization: A Macroscopic Approach to Complex Systems. Am. J. Phys. 1989, 57, 958. [CrossRef]

21. Haken, H. Advanced Synergetics; Springer: Berlin, Germany, 1983; ISBN 978-364-245-555-1.

22. Wu, T. Self-Organizing Methodology; Tsinghua University Press: Beijing, China, 2001; ISBN 978-730-204-422-2.

23. Wang, L.; Wang, Y. Research on the Condition Mechanism of Photovoltaic Industry Chain Risk Evolution Based on Dissipative Structure Theory. Soft Sci. 2018, 32, 21-26. [CrossRef]

24. De la Tour, A.; Glachant, M.; Ménière, Y. Innovation and international technology transfer: The case of the Chinese photovoltaic industry. Energy Policy 2011, 39, 761-770. [CrossRef]

25. Awate, S.; Ajith, V.; Ajwani-Ramchandani, R. Catch-up as a Survival Strategy in the Solar Power Industry. J. Int. Manag. 2018, 24, 179-194. [CrossRef]

26. Wang, H.; Wang, J.; Feng, Z. The economic effects of anti-dumping and anti-subsidy policies among china, the US and the EU: The photovoltaic industry. Singap. Econ. Rev. 2018, 63, 513-534. [CrossRef]

27. Zhang, L.; Wang, J.; Wen, H.; Fu, Z.; Li, X. Operating performance, industry agglomeration and its spatial characteristics of Chinese photovoltaic industry. Renew. Sustain. Energy Rev. 2016, 65, 373-386. [CrossRef]

28. Haley, U.C.V.; Schuler, D.A. Government Policy and Firm Strategy in the Solar Photovoltaic Industry. Calif. Manag. Rev. 2011, 54, 17-38. [CrossRef]

29. Chu, J.; Guo, B.; Zhao, Y. A GERT Model Considering Value Viscosity and for Stability Prediction of Closed-loop Photovoltaic Industry Chain System. Ind. Eng. Manag. 2018, 23, 122-129. [CrossRef]

30. Wang, Z.; Tan, Q.; Xu, X. The Evolution Model and Empirical Studies of Industrial System. Stat. Res. 2007, 2, 47-54. [CrossRef]

31. Shen, X. Research on the Evaluation of the Evolution Level of Industrial Ecological System in Yunnan Province. Econ. Res. Guide 2012, 8, 77-80.

32. Qiu, G.; Ding, M. Low-Carbon Development Level Evaluation under the Scope of Ecological Civilization: A Case of Sichuan Province. Ecol. Econ. 2016, 32, 204-209.

33. Wu, W.; Zhou, X. Establishment and Application of the Evaluation System of Inclusive Green Growth Performance in China. Chin. J. Manag. Sci. 2019, 27, 183-194. [CrossRef]

34. Gong, C.; Ying, P.; Li, W. Research on evaluation method of provincial science and technology development level based on dual driven. Stud. Sci. Sci. 2019, 37, 1589-1597. [CrossRef]

35. Wang, L.; Wang, Y. Research on the Co-evolution Dynamic Mechanism of Photovoltaic Industry Chain System. East. China Econ. Manag. 2017, 31, 170-177. [CrossRef]

36. Li, Y.; Du, J. Artificial Intelligence with Uncertainty; National Defense Industry Press: Beijing, China, 2005; ISBN 978-711-803-921-4.

37. Wang, L.; Wang, Y. Assessment on Industrial Chain Risk of Equipment Manufacturing Industry Based on Cloud Model. Technol. Econ. 2016, 35, 80-87. 
38. Chen, Y.; Yang, Y.; Du, D. Study on Performance Evaluation of Provincial Ecological Environment Based on Cloud Model. Soft Sci. 2018, 32, 100-108. [CrossRef]

39. Liu, S.; Xie, N. Grey System Theory and Its Application; Science Press: Beijing, China, 2008; ISBN 978-703-022-847-5.

40. Tang, W.; Xiang, C. The Improvements of Forecasting Method in GM $(1,1)$ Model Based on Quadratic Interpolation. Chin. J. Manag. Sci. 2006, 14, 110-112. [CrossRef]

41. Shi, P.; Li, X.; Xiong, Y. Coupling Measurement and Prospect Forecast of Regional "Beautiful China" Construction and Tourism Industry Development-A Case Study of 11 Provinces along the Yangtze River Economic Belt. China Soft Sci. 2018, 2, 86-102.

42. Hu, F.; Lu, L.; Huang, B. Research on Talent Demand Forecast of High-tech Industry in Jiangsu Province :Based on Improved Metabolic GM (1,1) Model. Sci. Technol. Manag. Res. 2018, 16, 57-62. [CrossRef]

43. Jin, Q.; Zheng, Q. Ecological Innovation Synergy Degree and Its Influencing Factors in the Yangtze River Economic Zone. Sci. Technol. Manag. Res. 2018, 18, 261-266. [CrossRef]

44. Ma, H.; Cao, X.; Li, X. Synergy Degree of Innovation Network of Emerging Technology Industry in Central China. Econ. Geogr. 2019, 3, 164-173. [CrossRef]

(C) 2020 by the authors. Licensee MDPI, Basel, Switzerland. This article is an open access article distributed under the terms and conditions of the Creative Commons Attribution (CC BY) license (http://creativecommons.org/licenses/by/4.0/). 